Original article

\title{
Characterization of sexually transmitted infections, their pharmacological treatment, and recurrence in a Colombian population
}

\author{
Luis Fernando Valladales-Restrepo ${ }^{1,2}$, Juan Alberto Ospina-Cano ${ }^{1}$, María José \\ Londoño-Serna ${ }^{1}$, Jorge Enrique Machado-Alba ${ }^{1}$ \\ ${ }^{1}$ Grupo de Investigación en Farmacoepidemiología y Farmacovigilancia, Universidad Tecnológica \\ de Pereira-Audifarma S.A, Pereira, Colombia \\ ${ }^{2}$ Grupo de Investigación Biomedicina, Facultad de Medicina, Fundación Universitaria \\ Autónoma de las Américas, Pereira, Colombia
}

Introduction: Sexually transmitted infections are a public health problem worldwide. Their inadequate antimicrobial management has been associated with a higher risk of recurrence. Objective: To characterize the main sexually transmitted infections, the adherence to clinical practice guidelines, and the factors associated with recurrence in Colombia. Materials and methods: We conducted an observational study to identify the main sexually transmitted infections, the sociodemographic variables, and the pharmacological management in a patient cohort from a population database of 6.5 million people affiliated with the Colombian health system. We made a multivariate analysis to identify the variables associated with recurrence.

Results: We detected 3,158 patients with a mean age of $41.8 \pm 14.5$ years, of whom $63.1 \%$ were men. We found 4.030 episodes of sexually transmitted infections, predominantly urethral syndrome $(27.5 \%)$. Only $13.6 \%$ of patients with urethral syndrome, ulcerative syndrome, or genital warts were managed in compliance with clinical practice guidelines and $20.6 \%$ were dispensed condoms; $16.7 \%$ of patients had recurrences and being male $(\mathrm{OR}=1.32 ; 95 \% \mathrm{Cl}$ $1.08-1.63),<30$ years old $(\mathrm{OR}=1.72 ; 95 \% \mathrm{Cl} 1.40-2.13)$, being treated in municipalities other than capital cities $(\mathrm{OR}=1.43 ; 95 \% \mathrm{Cl} 1.06-1.94)$, and having received inadequate treatment for the first episode $(\mathrm{OR}=1.93 ; 95 \% \mathrm{Cl} 1.52-2.39)$ were associated with recurrence.

Conclusions: The majority of patients with sexually transmitted infections were not treated in compliance with clinical practice guidelines and those who did not have adequate management had a higher risk of recurrence.

Keywords: Sexually transmitted diseases; urethritis; recurrence; male; condoms; public health.

Received: 30/11/2020

Accepted: $12 / 07 / 2021$

Published: 21/07/2021

Citation:

Valladales-Restrepo LF, Ospina-Cano JA, LondoñoSerna MJ, Machado-Alba JE. Characterization of sexually transmitted infections, their pharmacological treatment, and recurrence in a Colombian population Biomédica. 2021;41(Suppl.2):130-9.

https://doi.org/10.7705/biomedica.5872

\section{Corresponding author:}

Jorge Enrique Machado-Alba, Grupo de Investigación en Farmacoepidemiología y

Farmacovigilancia, Universidad Tecnológica de Pereira-Audifarma S.A, Calle 105 № 14-140, Pereira, Risaralda, Colombia

Telephone: (57) (310) 832 6970; fax: (576) 3137822 machado@utp.edu.co

\section{Author contributions:}

Jorge Enrique Machado-Alba and Luis Fernando Valladales-Restrepo: data collection and analysis Jorge Enrique Machado-Alba: critical revision and evaluation of the final version of the manuscript All authors participated in the drafting, the description of results, and the discussion of the manuscript.

Funding:

This study did not receive funding.

Conflicts of interest:

The authors declare no conflicts of interest
Caracterización de las infecciones de transmisión sexual, su tratamiento farmacológico y la recurrencia en una población colombiana

Introducción. Las infecciones de transmisión sexual constituyen actualmente un problema de salud pública en el mundo. Su inadecuado tratamiento antimicrobiano se ha relacionado con un mayor riesgo de recurrencias.

Objetivo. Caracterizar las principales infecciones de transmisión sexual, el cumplimiento de las guías de práctica clínica de Colombia y los factores asociados con las recurrencias. Materiales y métodos. Se hizo un estudio observacional para determinar las principales infecciones de transmisión sexual, las variables sociodemográficas y el tratamiento farmacológico en una cohorte de pacientes registrados en una base de datos poblacional de 6,5 millones de personas afiliadas al Sistema de Salud de Colombia. Se hizo un análisis multivariado para establecer las variables asociadas con las recurrencias.

Resultados. Se detectaron 3.158 pacientes; su edad media era de $41,8 \pm 14,5$ años y $63,1 \%$ de ellos correspondía a hombres; se encontraron 4.030 episodios de infecciones de transmisión sexual con predominio del síndrome uretral (27,5\%). El 13,6 \% de los pacientes con síndrome uretral, ulceroso o con verrugas genitales se manejó según las guías de práctica clínica. El 20,6 \% tenía acceso a condones y el 16,7\% presentó recurrencias. Ser hombre $\left(\mathrm{OR}=1,32 ; \mathrm{IC}_{95 \%} 1,08-1,63\right)$, tener $<30$ años $\left(\mathrm{OR}=1,72 ; \mathrm{IC}_{95 \%} 1,40-2,13\right)$, ser tratado en municipios distintos a ciudades capitales $\left(\mathrm{OR}=1,43 ; \mathrm{IC}_{95 \%}, 1,06-1,94\right)$ y haber recibido un tratamiento inadecuado en el primer episodio $\left(\mathrm{OR}=1,93 ; \mathrm{IC}_{95 \%}, 1,52-2,39\right)$ fueron factores asociados con las recurrencias.

Conclusiones. La mayoría de los pacientes con infecciones de transmisión sexual no fueron tratados según las guías de práctica clínica y quienes no tuvieron un manejo adecuado presentaban mayor riesgo de recurrencias.

Palabras clave: enfermedades de transmisión sexual; uretritis; recurrencia; masculino; condones; salud pública. 
Sexually transmitted diseases are a variety of clinical syndromes and infections caused by pathogens transmitted during sexual intercourse (1). In recent years, many experts have suggested calling them sexually transmitted infections instead because the concept of disease involves a medical problem, usually with clear signs and symptoms, while sexually transmitted diseases also affect asymptomatic patients and, therefore, not all infections can be considered diseases $(2,3)$.

Sexually transmitted infections are among the most common contagious conditions affecting individuals' health and lives around the world $(4,5)$ and they are currently considered a global public health problem (5). Sexually transmitted infections prevalence depends on socioeconomic conditions, cultural and moral beliefs, and diagnostic and therapeutic options (3). According to the World Health Organization (WHO), every day, more than a million people acquire a sexually transmitted infection, and it has been estimated that 376 million new sexually transmitted infections cases occurred in 2016, among them, trichomoniasis (156 million), chlamydia (127 million), gonorrhea (87 million), and syphilis (6.3 million). Besides, the number of people with genital herpes exceeds 500 million and approximately 240 million suffer from chronic hepatitis B (6). In 2016, the prevalence of chlamydia infection in Colombian men was $9.2 \%$ and $7.4 \%$ among women while syphilis prevalence was $1.2 \%$ overall while gonorrhea prevalence was $0.7 \%$ in women and $0.6 \%$ in men $(7)$.

These infections can cause acute urogenital conditions such as urethritis, cervicitis, vaginitis, and ulceration in the genitals, among others, and some may involve the rectum and pharynx. Several etiological agents are associated with serious short- and long-term complications (4). Sexually transmitted infections can be caused by viruses, bacteria, and parasites; they include mainly eight infections, four of which can be cured, namely, syphilis, gonorrhea, chlamydia, and trichomoniasis while the other four are caused by viruses (hepatitis B, herpes simplex, HIV and human papillomavirus) and are incurable, although there are treatments to attenuate, control, or modify the symptoms or the disease $(6,8)$.

The lack of treatment is also considered a public health problem because untreated infections can lead to harmful consequences for individuals' health (9). In this sense, the Colombian Ministry of Health and Social Protection and the Administrative Department of Science, Technology, and Innovation (Colciencias) published in 2013 the clinical practice guidelines for the syndromic approach to the diagnosis and treatment of patients with sexually transmitted infections and other genital tract infections aimed at providing health professionals with evidence on therapy effectiveness and safety to reduce the variability found in clinical practice, among other objectives (10). However, few studies in the country have addressed this topic and the pharmacological management indicated for patients with sexually transmitted infections is unknown. Therefore, we sought to characterize the main sexually transmitted infections, the adherence of their treatment to clinical practice guidelines, and the factors associated with recurrence in a Colombian population.

\section{Materials and methods}

\section{Study design}

We conducted an observational, descriptive, and retrospective cohort study on the treatment schemes used in the management of some sexually transmitted 
infections and their recurrence. Data were obtained from a population database of drugs dispensed that gathers information from about 6.5 million individuals affiliated with the contributory regime of the Colombian Health System through five insurers known in the country as health-promoting companies corresponding to approximately $30.0 \%$ of the actively affiliated population in this regime in the country and $14.3 \%$ of the Colombian total population.

We selected patients of either sex aged 14 or older treated in outpatient units from January 1 to December 31, 2015. We excluded those who had had a sexually transmitted infection in 2013 or 2014 . We followed the patients until June 30, 2019. Besides, we analyzed the International Classification of Diseases, $10^{\text {th }}$ revision (ICD-10) codes related to sexually transmitted infections and the drugs prescribed for their management.

The ICD-10 diagnostic codes used for patient identification were the following:

- Urethral discharge syndrome and/or cervicitis:

» Urethritis: N341, N342, N370

»Gonococcal infections: A540-A542, A546-A549

»Chlamydial infections: A560-A563, A568

" Trichomoniasis: A590, A598, A599

- Ulcerative syndrome:

» Syphilis: A510-A512, A539, N742

»Genital herpes: A600, A601, A609

"Soft chancre: A57X

» Lymphogranuloma venereum: A55X

"Granuloma inguinale: A58X

»Anogenital warts: A630

- Others:

»Hepatitis B: B160-B162, B169, B170, B180, B181

» Hepatitis C: B171, B182

»HIV: B200-B213, B217-B222, B227, B230-B232, B238, B24X, F024, R75X.

Based on the information on the use of drugs by the affiliated population, systematically recorded by the dispensing company Audifarma SA, we designed a database to collect the following groups of variables:

1. Sociodemographic: sex, age, city of dispensation.

2. Chronic comorbidities: we identified the main cardiovascular, endocrine, rheumatic, urological, kidney, psychiatric, neurological, digestive, respiratory, and neoplastic diseases from the reported ICD-10 diagnostic codes.

3. Drugs used in the management of some sexually transmitted infections. Management was considered adequate when the prescribed antibiotic, dose, and duration of treatment followed the Colombian clinical practice guidelines (10), as follows:

»Urethral discharge syndrome or cervicitis:

»Urethritis: ceftriaxone (500 mg IM single dose) and azithromycin (1 g orally single dose)

» Gonococcal infections: ceftriaxone (500 mg IM single dose) or spectinomycin ( $2 \mathrm{~g}$ IM single dose) 
»Chlamydial infections: azithromycin ( $1 \mathrm{~g}$ orally single dose) or doxycycline (100 mg orally administered every 12 hours for 7 days)

» Trichomoniasis: tinidazole ( $2 \mathrm{~g}$ oral single dose) or metronidazole (2 g orally single dose)

»Ulcerative syndrome:

»Syphilis: benzathine penicillin G (2,400,000 IU single-dose IM) or doxycycline (100 mg orally administered every 12 hours for 14 days)

» Genital herpes: acyclovir ( $200 \mathrm{mg}$ orally administered 5 times a day for 6-7 days) or valaciclovir ( $1 \mathrm{~g}$ orally administered every 12 hours for 7-10 days)

»Soft chancre: azithromycin ( $1 \mathrm{~g}$ orally single dose) or ceftriaxone (250 mg IM single dose) or erythromycin (500 mg orally administered every 8 hours for 7 days)

" Lymphogranuloma venereum or granuloma inguinale: azithromycin ( $1 \mathrm{~g}$ orally administered once a week for 3 weeks) or doxycycline (100 mg orally administered 2 times a day for 21 days)

»Anogenital warts (1): podophyllin or trichloroacetic acid

» HIV, hepatitis B and C pharmacological management was not taken into account.

4. Inadequate management: All patients who did not receive pharmacological management and those who received another type of antimicrobial therapy not recommended by the clinical practice guidelines $(1,10)$.

5. Recurrence: Patients with two or more sexually transmitted infection episodes through the follow-up period were considered recurrent.

6. Dispensing of hormonal contraceptives (oral, injectable, or depot) and/ or condoms.

\section{Data analysis}

The data were analyzed with the SPSS Statistics, version 26.0 program for Windows (IBM, USA). We made a descriptive analysis with frequencies and proportions for the qualitative variables and measures of central tendency and dispersion for the quantitative variables. The quantitative variables were compared using the Student's t-test or variance analysis and the categorical variables using the $\chi^{2}$ test. The binary logistic regression models used the presence of two or more sexually transmitted infections episodes (recurrence) as a dependent variable and those variables significantly associated with recurrence in the bivariate analyses as covariates. We adopted $p<0.05$ as the statistical significance level.

\section{Bioethical considerations}

The protocol was approved by the Bioethics Committee of the Universidad Tecnológica de Pereira under the category of risk-free research (approval code: 01-071019). We adhered to the ethical principles established by the Declaration of Helsinki and used no personal patient data.

\section{Results}

We identified 3,158 patients with a sexually transmitted infections diagnosis distributed in 64 different cities or municipalities of whom $63.1 \%(n=1994)$ were men. The mean age was $41.8 \pm 14.5$ years (range:14.0-96.8 years) distributed in the following age groups: $<30$ years ( $n=760 ; 24.1 \%), 30-49$ years 
$(n=1566 ; 49.6 \%), 50-64$ years $(n=568 ; 18.0 \%)$, and $\geq 65$ years $(n=264 ; 8.4 \%)$; $90.4 \%(n=2,856)$ of the patients resided in capital cities.

During the selection period and the follow-up, we found 4,030 sexually transmitted infections episodes, predominantly urethral syndrome $(n=1108$; $27.5 \%)$ distributed as follows: urethritis $(n=912 ; 22.6 \%)$, gonorrhea $(n=136$; $3.4 \%)$, chlamydia $(n=32 ; 0.8 \%)$, and trichomoniasis $(n=28 ; 0.7 \%)$ followed by ulcerative syndrome $(n=1,105 ; 27.4 \%)$ : syphilis $(n=555 ; 13.8 \%)$, genital herpes $(n=540 ; 13.4 \%)$, and chancre $(n=10 ; 0.3 \%)$, as well as genital warts $(n=939$; $23.3 \%), \operatorname{HIV}(n=808 ; 20.0 \%)$, and hepatitis B or C $(n=70 ; 1.7 \%) ; 83.3 \%$ $(n=2630 / 3158)$ of the patients had a single sexually transmitted infections episode while $16.7 \%$ ( $n=528)$ had two or more. At some point during followup, $20.6 \%(n=649)$ of the patients were dispensed condoms and $21.0 \%$ $(n=245 / 1164)$ of the women, hormonal contraceptives, mostly oral ones $(n=210 / 1164 ; 18.0 \%)$.

\section{Sexually transmitted infections pharmacological management}

A $13.6 \%$ (428/3152) of the urethral syndrome, ulcerative syndrome, and genital warts episodes were adequately managed. Genital warts were the most frequently treated in compliance with the clinical practice guidelines $(n=256 / 939 ; 27.3 \%)$ followed by genital herpes $(n=85 / 540 ; 15.7 \%)$, syphilis $(n=71 / 555 ; 12.8 \%)$, gonorrhea $(n=14 / 136 ; 10.3 \%)$, and soft chancre $(n=2 / 10$; $20.0 \%$ ). No episode of urethritis, chlamydia, or trichomoniasis was managed with the recommended antibiotic, dose, and treatment duration. Tables 1 , 2 , and 3 show the main drugs used for the treatment of urethral syndrome, ulcerative syndrome, and genital warts.

\section{Comorbidities}

A total of $68.1 \%(n=2,151)$ of patients had some chronic pathology. Cardiovascular diseases were the most frequent $(n=1,382 ; 43.8 \%)$ followed by endocrine $(n=845 ; 26.8 \%)$ and digestive disorders $(n=541 ; 17.1 \%)$.

Table 1. Pharmacological management of episodes of ulcerative syndrome in 3,158 patients with sexually transmitted infections, Colombia

\begin{tabular}{lrr}
\hline Syphilis (N=555) & $\mathbf{n}$ & \% \\
\hline Medications included in the management guide & 361 & 65.0 \\
Benzathine penicillin G & 337 & 60.7 \\
Doxycycline & 24 & 4.3 \\
Other antimicrobial management guide & 92 & 16.6 \\
No antimicrobial handling & 102 & 18.4 \\
\hline Genital herpes (N=540) & $\mathbf{n}$ & $\%$ \\
\hline Medications included in the management guide & 443 & 82.0 \\
Acyclovir & 414 & 76.7 \\
Valaciclovir & 29 & 5.4 \\
Other antimicrobial management guide & 37 & 6.9 \\
No antimicrobial handling & 60 & 11.1 \\
\hline Soft chancre (N=10) & $\mathbf{n}$ & $\%$ \\
\hline Medications included in the management guide & 6 & 60.0 \\
Azithromycin & 3 & 30.0 \\
Erythromycin & 2 & 20.0 \\
Ceftriaxone & 1 & 10.0 \\
Other antimicrobial management guide & 4 & 40.0 \\
No antimicrobial handling & 0 & 0.0 \\
\hline
\end{tabular}


Table 2. Pharmacological management guide of episodes of urethral syndrome in 3,158 patients with sexually transmitted infections, Colombia

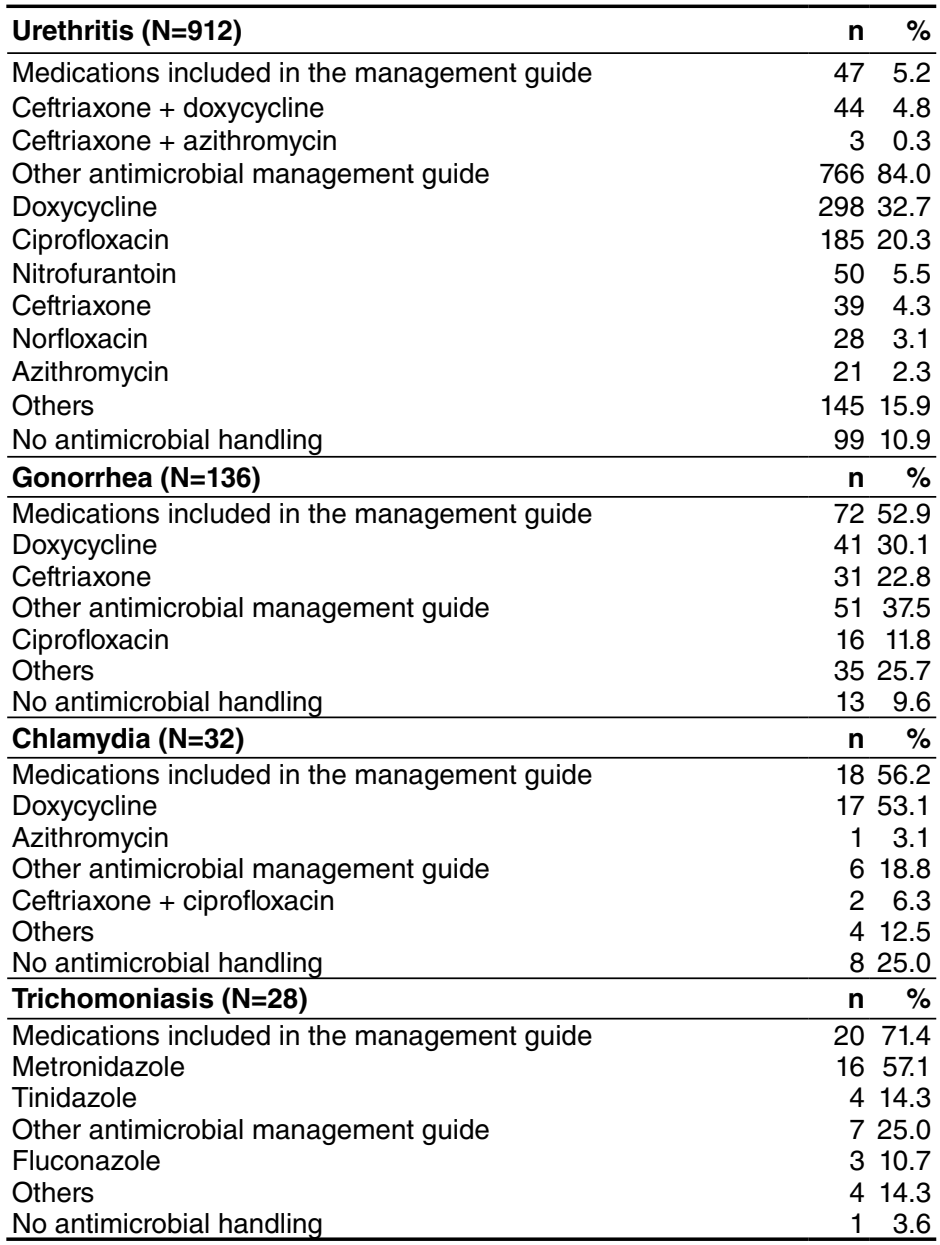

Table 3. Pharmacological management guide of episodes of genital warts in 3,158 patients with sexually transmitted infections, Colombia

\begin{tabular}{lrr}
\hline Genital warts $(\mathbf{N}=\mathbf{9 3 9})$ & $\mathbf{n}$ & $\mathbf{\%}$ \\
\hline Medications included in the management guide & 314 & 33.4 \\
Podophyllin & 314 & 33.4 \\
Trichloroacetic acid & 0 & 0.0 \\
Other antimicrobial management guide & 429 & 45.7 \\
Silver sulfadiazine & 154 & 16.4 \\
Clotrimazole & 93 & 9.9 \\
Metronidazole & 61 & 6.5 \\
Others & 121 & 12.9 \\
No antimicrobial handling & 196 & 20.9 \\
\hline
\end{tabular}

\section{Multivariate analysis}

The binary logistic regression analysis showed that being a man under 30 years of age, being treated in municipalities other than capital cities, and having received inadequate treatment for the first sexually transmitted infections episode, were associated with a higher probability of another episode during the follow-up period. No variable was protective against this risk (table 4). 
Table 4. Multivariate analysis of the variables associated with the recurrence of sexually transmitted infections

\begin{tabular}{|c|c|c|c|c|}
\hline \multirow{2}{*}{ Variables } & \multirow{2}{*}{ Sig } & \multirow{2}{*}{ OR } & \multicolumn{2}{|c|}{$95 \% \mathrm{Cl}$} \\
\hline & & & Lower & Upper \\
\hline Age $<30$ years & $<0,001$ & 1.729 & 1.403 & 2.132 \\
\hline Man & 0.007 & 1.327 & 1.080 & 1.631 \\
\hline Treatment in municipalities & 0.018 & 1.439 & 1.064 & 1.947 \\
\hline Endocrine diseases & 0.077 & 0.811 & 0.643 & 1.023 \\
\hline Having received inadequate treatment in & $<0,001$ & 1.913 & 1.528 & 2.395 \\
\hline Condom dispensing & 0.187 & 1.167 & 0.928 & 1.467 \\
\hline
\end{tabular}

Sig: statistical significance; OR: odds ratio; Cl95\%: confidence interval 95\%

\section{Discussion}

The main sexually transmitted diseases frequencies, their pharmacological treatment in compliance with the country's clinical practice guidelines, and the factors associated with having two or more episodes were identified in a cohort of patients from both sexes aged 14 and older in a Colombian population.

Similar to our report, in a study in Spain, $27.1 \%$ of the patients had urethral syndrome (11), and the most frequently found sexually transmitted infection was genital warts in agreement with the rate reported by Jacob, et al. in Germany (51.2\%) (12) but differing from that found in Belgium, where the most common sexually transmitted infection was chlamydial infection (43.1\%) (13). According to WHO reports $(4,6)$ and to a prevalence study from Colombia $(7)$, infections caused by Chlamydia trachomatis are the most common infections in both men and women. However, in our study, chlamydial infections were found in less than $1 \%$ of cases due perhaps to the fact that patients were classified according to the ICD-10 codes and many of the sexually transmitted infections classified as unspecified urethritis were likely chlamydial infections.

Only $13.6 \%$ of the urethral syndrome, ulcerative syndrome, and genital warts cases treatment adhered to the clinical practice guidelines on antibiotic choice, dose, and duration. Inadequate treatment, including the use of incorrect antibiotics or sub-therapeutic doses, can lead to multiple treatments for the same infection generating an excessive burden on the health system, promoting the development of resistance to antibiotics, and reducing the effectiveness of current treatments (9).

The information on this worrisome problem is limited. However, in England, Wetten, et al. found that between 2000 and 2011, the proportion of patients treated for chlamydial infections increased from 59.5 to $78.4 \%$ and that more than $90 \%$ of them were prescribed the recommended antibiotics; in turn, $32.7-53.6 \%$ of patients diagnosed with gonorrhea received antibiotic treatment but, although ciprofloxacin was discontinued as the recommended therapy in 2005, the authors found that it was prescribed in $42 \%$ of the cases in 2007 and in $20 \%$ in 2011 (14). In New Zealand, 65\% of patients with gonorrhea episodes were managed in compliance with the country guidelines and the adherence was greater in patients treated at sexual health clinics (89\%) than at general medicine clinics (52\%) (15). From 2011 to $2014,50-52 \%$ of patients with gonorrhea in England were managed according to the guidelines (16). In contrast, in the Netherlands, $93.3 \%$ of patients with gonorrhea were treated with ceftriaxone in compliance with the practice guidelines (17) while in Estonia, $48.6 \%$ of treatments for gonorrhea did not comply with the clinical practice guidelines and $3.8 \%$ were noncompliant for chlamydia (9). 
Recurrence is among the problems related to inadequate sexually transmitted infections pharmacological management $(3,9)$. In Belgium, reinfections occurred in 15.4\% of patients (13); in Brazil in 13.6\% (18); in Canada in $6.4 \%$ (19), and in our study in $17.6 \%$ and we documented a $91 \%$ increase in the risk of recurrence when the recommended medication was not administered or when no antimicrobial treatment was indicated. In the United States, Amiri, et al. determined that the factors associated with not receiving treatment were being a woman $(\mathrm{OR}=1.25 ; 95 \% \mathrm{Cl} 1.05-1.50)$ and residing in a small town $(\mathrm{OR}=1.49 ; 95 \% \mathrm{Cl} 1.20-1.86)(20)$.

In general, sexually transmitted infections are found more frequently in men as reported in Belgium (57.3\%) (13), but contrary to other studies where they predominated in women (21-23). According to several studies, being a man is a risk factor for sexually transmitted infections recurrences as informed in Brazil (OR=4.28; 95\% Cl 1.31-14.0) (18), England (OR=9.9; 95\% Cl 1.3273.78) (24), Spain ( $\mathrm{HR}=1.9 ; 95 \% \mathrm{Cl} 1.3-2.8)(25)$, and in our study (OR=1.32; $95 \% \mathrm{Cl} 1.08-1.63)$. In addition, those under 25 are considered a high-risk population for sexually transmitted infections $(8,20)$ given that according to incidence estimates in the US, about $50 \%$ of infections occur in women and men aged 15-24 years (22). In Spain, López, et al. found that being less than 20 years $(\mathrm{HR}=4.1 ; 95 \% \mathrm{Cl} 2.1-8.0)$ was a risk factor for chlamydial reinfections (25), which agrees with our findings that those under 30 years had a $72 \%$ risk of having a new sexually transmitted infection episode. Older people are more aware of the importance of reproductive health care and of prevention, detection, and treatment of these infections (20), so they tend to have stable relationships and use condoms more frequently (8).

The use of condoms is one of the main strategies to reduce sexually transmitted infection transmission, but a reduction in their use has been documented among the younger population (8). We found that one-fifth of the patients in our study were dispensed condoms in contrast with the case of Brazil, where $76.2 \%$ of people reported their use, although only $9.1 \%$ used them regularly (18). In Almeida, et al.'s (18) and our study, condom use was not a protective factor against recurrence, maybe because of its inappropriate and/or inconsistent use (8).

Our results should be cautiously interpreted since we did not have access to the medical records to confirm sexually transmitted infections etiological or clinical diagnoses. Additionally, we had no data on the education level, the number of sexual partners, the use of illicit drugs, or on antimicrobials, contraceptives, or condoms prescribed outside the health system or not delivered by the dispensing company, nor on the antiviral management received by HIV and hepatitis patients. Finally, it was not possible to establish whether the recurrence was due to the lack of treatment of the sexual partner or partners or to a de novo infection.

We concluded that the majority of sexually transmitted infection patients in our study were not treated in compliance with the Colombian clinical practice guidelines and that those not receiving adequate management had a higher risk of recurrence, as well as men, adolescents, and young adults. For the comprehensive management of sexually transmitted infection patients, prescribing physicians should appropriately select the antibiotic, dose, and duration of treatment to avoid recurrence. The prescription should be based on the available clinical practice guide. The continuous and autonomous updating of medical professionals is very important and health administrators 
can also play a relevant role in promoting the updating of their prescribers. On the other hand, more studies on antibiotic sensitivity and resistance patterns are required as they are essential for proposing updates in the country's clinical practice guidelines.

\section{Acknowledgments}

We thank Soffy Claritza López for obtaining the database.

\section{References}

1. Sexually Transmitted Diseases. Summary of 2015 CDC Treatment Guidelines. J Miss State Med Assoc. 2015;56:372-5.

2. American Sexual Health Association. STDs/STIs. Accessed on: June 1, 2020. Available from: http://www. ashasexualhealth.org/stdsstis/

3. Buder S, Schöfer H, Meyer T, Bremer V, Kohl PK, Skaletz-Rorowski A, et al. Bacterial sexually transmitted infections. J Dtsch Dermatol Ges. 2019;17:287-315. https://doi.org/10.1111/ddg. 13804

4. Rowley J, Vander Hoorn S, Korenromp E, Low N, Unemo M, Abu-Raddad LJ, et al. Chlamydia, gonorrhoea, trichomoniasis and syphilis: Global prevalence and incidence estimates, 2016. Bull World Health Organ. 2019;97:548-62.

https://doi.org/10.2471/BLT.18.228486

5. de Amorim TF, Teles SA, Moraes LC, de Matos MA, Carneiro M, Nogueira DJ, et al. Symptomatic sexually transmitted infections in Brazil's emerging rural populations. J Assoc Nurses AIDS Care. 2018;29:942-8. https://doi.org/10.1016/j.jana.2018.05.004

6. World Health Organization. Report on global sexually transmitted infection surveillance, 2018. Accessed on: June 1, 2020. Available from: https://www.who.int/reproductivehealth/ publications/stis-surveillance-2018/en/

7. Korenromp EL, Ríos C, Apolinar ALS, Caicedo S, Cuéllar D, Cárdenas I, et al. Prevalence and incidence estimates for syphilis, chlamydia, gonorrhea, and congenital syphilis in Colombia, 1995-2016. Rev Panam Salud Pública. 2018;42:e118. https://doi.org/10.26633/RPSP.2018.118

8. Sieving RE, Gewirtz O'Brien JR, Saftner MA, Argo TA. Sexually transmitted diseases among us adolescents and young adults: Patterns, clinical considerations, and prevention. Nurs Clin North Am. 2019;54:207-25. https://doi.org/10.1016/j.cnur.2019.02.002

9. Tisler-Sala A, Ojavee SE, Uusküla A. Treatment of chlamydia and gonorrhoea, compliance with treatment guidelines and factors associated with non-compliant prescribing: Findings form a cross-sectional study. Sex Transm Infect. 2018;94:298-303.

https://doi.org/10.1136/sextrans-2017-053247

10. Ministerio de Salud y Protección Social - Colciencias. Guía de práctica clínica para el abordaje sindrómico del diagnóstico y tratamiento de los pacientes con infecciones de transmisión sexual y otras infecciones del tracto genital, 2013. Accessed on: June 1, 2020. Available from: https://www.minsalud.gov.co/sites/rid/Lists/BibliotecaDigital/RIDE/INEC/IETS/ profesionales\%20salud.pdf

11. Moreno-Ribera N, Fuertes-de Vega I, Blanco-Arévalo JL, Bosch-Mestres J, GonzálezCordón A, Estrach-Panella T, et al. Sexually transmitted infections: Experience in a multidisciplinary clinic in a tertiary hospital (2010-2013). Actas Dermosifiliogr. 2016;107:23541. https://doi.org/10.1016/j.ad.2015.10.007

12. Jacob L, Duse DA, Kostev K. Prevalence and treatment of sexually transmitted infections in men followed by urologists in Germany - a cross sectional study with 347,090 men. Ger Med Sci. 2018;16:1-7. https://doi.org/10.3205/000265

13. Boffin N, Moreels S, Deblonde J, van Casteren V. Four sexually transmitted infections (STIs) in Belgian general practice: First results (2013-2014) of a nationwide continuing surveillance study. BMJ Open. 2017;7:e012118. https://doi.org/10.1136/bmjopen-2016-012118

14. Wetten S, Mohammed H, Yung M, Mercer CH, Cassell JA, Hughes G. Diagnosis and treatment of chlamydia and gonorrhoea in general practice in England 2000-2011: A population-based study using data from the UK Clinical Practice Research Datalink. BMJ Open. 2015;5:e007776. https://doi.org/10.1136/bmjopen-2015-007776 
15. Forster R, Ng D, Upton A, Franklin R, Thomas M. Treatment of gonorrhoea in Auckland, New Zealand: Marked variation in prescriber adherence to treatment guidelines. Intern Med J. 2017;47:640-8. https://doi.org/10.1111/imj.13433

16. Mohammed H, Sile B, Furegato M, Fifer H, Hughes G. Poor adherence to gonorrhoea treatment guidelines in general practice in England. Br J Gen Pract. 2016;66:352. https://doi.org/10.3399/bjgp16X686077

17. van Amerongen R, Gazendam RP, van Bergen JEAM. Trends in antimicrobial management of gonorrhoea by general practitioners in Amsterdam, the Netherlands, between 2010 and 2016: A cross-sectional study. BMC Fam Pract. 2019;20:12. https://doi.org/10.1186/s12875-018-0900-9

18. Almeida VC, Donalisio MR, Cordeiro R. Factors associated with reinfection of syphilis in reference centers for sexually transmitted infections. Rev Saúde Pública. 2017;51:64. https://doi.org/10.1590/S1518-8787.2017051006432

19. Généeux $M$, Leclerc $P$, Bédard L, Allard R. Upsurge of chlamydial reinfection in a large Canadian city: An indication of suboptimal Chlamydia screening practices? Can J Public Health. 2010;101:420-4. https://doi.org/10.1007/BF03404865

20. Amiri S, Pham CD, Amram O, Alcover KC, Oluwoye O, Bravo L, et al. Proximity to screening site, rurality, and neighborhood disadvantage: Treatment status among individuals with sexually transmitted infections in Yakima County, Washington. Int J Environ Res Public Health. 2020;17:2679. https://doi.org/10.3390/ijerph17082679

21. Panchanadeswaran S, Johnson SC, Mayer KH, Srikrishnan AK, Sivaran S, Zelaya CE, et al. Gender differences in the prevalence of sexually transmitted infections and genital symptoms in an urban setting in southern India. Sex Transm Infect. 2006;82:491-5. https://doi.org/10.1136/sti.2006.020768

22. Satterwhite CL, Torrone E, Meites E, Dunne EF, Mahajan R, Ocfemia MC, et al. Sexually transmitted infections among US women and men: Prevalence and incidence estimates, 2008. Sex Transm Dis. 2013;40:187-93. https://doi.org/10.1097/OLQ.0b013e318286bb53

23. Sonnenberg P, Clifton S, Beddows S, Field N, Soldan K, Tanton C, et al. Prevalence, risk factors, and uptake of interventions for sexually transmitted infections in Britain: Findings from the National Surveys of Sexual Attitudes and Lifestyles (Natsal). Lancet. 2013;382:1795-806. https://doi.org/10.1016/S0140-6736(13)61947-9

24. Dolan G, Chauhan M, Foster K, Basta M, Bushby S, White C, et al. Factors associated with repeat diagnosis of syphilis in genitourinary medicine (GUM) clinic attendees in the North East of England, 2002-2014. Int J STD AIDS. 2018;29:790-99. https://doi.org/10.1177/0956462418757554

25. López-de-Munain J, Cámara-Pérez MD, Imaz-Pérez M, Pereda-Berroeta J, López-Azcarreta I, Muñoz-Sánchez J, et al. Chlamydia trachomatis re-infection in Spain: A STI clinic-based cohort study. Enferm Infecc Microbiol Clin. 2017;35:165-73.

https://doi.org/10.1016/j.eimc.2016.08.011 